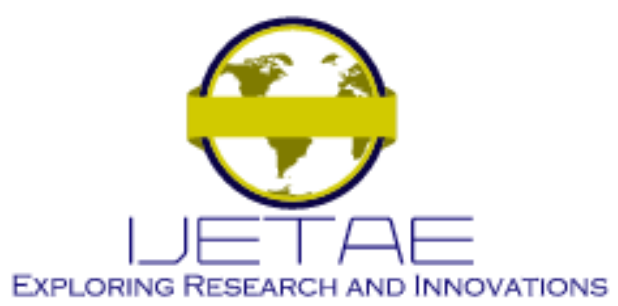

International Journal of Emerging Technology and Advanced Engineering

Website: www.ijetae.com (E-ISSN 2250-2459, Scopus Indexed, ISO 9001:2008 Certified Journal, Volume 12, Issue 02, February 2022)

Manuscript Received: 02 January 2022, Received in Revised form: 01 February 2022, Accepted: 05 February 2022

DOI: $10.46338 /$ ijetae0222_09

\title{
Implementation of Machine Learning in Health Management to Improve the Process of Medical Appointments in Perú
}

\author{
Edwin Jose Kcomt-Ponce ${ }^{1}$, Enrique Lee Huamaní ${ }^{2}$, Alexi Delgado ${ }^{3}$ \\ ${ }^{I}$ Systems Engineer Program, Universidad De Ciencias Y Humanidades, Lima-Perú \\ ${ }^{2}$ Image Processing Research Laboratory, Universidad De Ciencias Y Humanidades, Lima Perú \\ ${ }^{3}$ Mining Engineering Section, Pontificia Universidad Católica Del Perú, Lima-Perú
}

\begin{abstract}
The Peruvian health system has presented various deficiencies, one in particular is the difficulty and time for a user to schedule a medical appointment, in various health centers nationwide it is a problem for many citizens to easily access the health service. This research proposes developing a mobile app that allows automating this process by streamlining the procedures that lead to good health management to optimize both financial and human resources for better performance, quality and user experience that is insured at the service of ESSALUD. The results show that digital transformation and modernization with the support of technology significantly improve health management and therefore the medical appointment process, as well as other aspects that reduce the time of care and guarantee a reduction in the administrative work of the personnel of health allowing them to spend more time in patient care.
\end{abstract}

Keywords - artificial intelligence; health; health management; machine learning; medical appointment

\section{INTRODUCTION}

If there is something that has always been questioned by the population, it is health management in the country and even more so in the process to book a medical appointment and be treated, according to a survey carried out by the National Superintendency of Health (SUSALUD) in 2016, with a sample of 25,753 interviewees, they consider that one of the main problems is the delay in care due to excessive waiting times to obtain an appointment, where $43.5 \%$ believe that the service should be improved dating and admission [1].

On March 5, 2020 in Peru, the first case of COVID-19 is confirmed from that date onwards, the SARS-CoV-2 virus began to spread to all corners of the country and put the Peruvian health system to the test, leaving in evidences a set of difficulties and shortcomings that have afflicted the Peruvian population for many years [2].
In addition to this, the national emergency situation also demonstrated the Peruvian reality in various aspects both economic, social and in the particular case of health, a terribly neglected system, with a minimal and totally fragmented budget where inequality prevails for the right to health of thousands of Peruvians [3].

After approximately 2 years have elapsed since the first case reported in the country, the shortage of supplies and human resources to meet the demand of patients in the different health facilities nationwide was more than notorious, which led to the cancellation of Scheduled appointments of patients who presented other types of health problems, the lack of care and the problems faced by each establishment brought with it an increase in morbidity and mortality rates and in turn the dissatisfaction of the population [4].

Technology and medicine in recent years have worked hand in hand and as an example of this we can point to artificial intelligence as a great support tool for health, artificial intelligence allows us to handle a large amount of information efficiently and quick [5].

The Jorge Tadeo Lozano University of Colombia and one of its students developed a project through machine learning that is a branch of artificial intelligence that allows using information to predict results, for the present case, the system revealed the most demanded specialties for the scheduling of appointments in the coming weeks and thus be able to define classification models that facilitate forecasts against scheduled appointments [6]. For his part, a student from the National University of San Martin in Peru presented a project on neural networks that are an artificial intelligence model, improving the reservation of medical appointments and reducing patient care time by quickly identifying symptoms and in this way assign it to the specialty in which it will be attended [7]. 


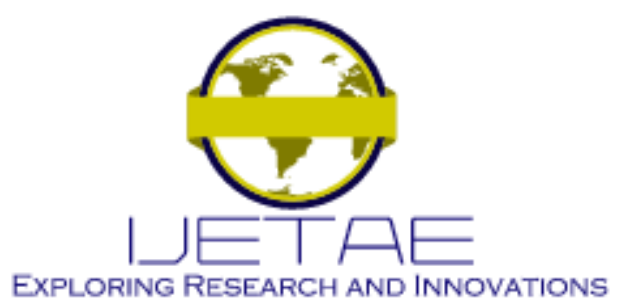

International Journal of Emerging Technology and Advanced Engineering

Website: www.ijetae.com (E-ISSN 2250-2459, Scopus Indexed, ISO 9001:2008 Certified Journal, Volume 12, Issue 02, February 2022)

Again in Colombia this time by the Francisco José de Caldas District University carried out a project to implement a virtual agent through telephony and mobile app for scheduling medical appointments, managing to offer patients a new communication channel through a chatbot that used artificial intelligence for user interaction [8].

Therefore, the objective of this research work is to develop an application that takes advantage of artificial intelligence to improve the process of medical appointments in the public health sector of Peru, thus managing to manage programming in a more organized and faster way. of appointments allowing to prioritize cases per patient according to their health problem, reducing not only waiting times to be seen but also the impact of the disease on patients.

The realization of this project is possible through the management of various tools, technologies and requirements that allow a correct and optimal development of the application in a set time, for that reason the framework to use will be SCRUM that allows an agile methodology in the project processes, in addition to having the advantages provided by the use of machine learning for data analysis and prediction, for programming the $\mathrm{C}$ \# language is used with the .NET framework and SQL Server 2019 to manage the database. of data.

\section{Methodology}

\section{A. Scrum}

This framework implies a process management to tackle complex projects that require dynamic environments, so they demand speed of results and flexibility. It is an agile work methodology that has several objectives and that allows us to accelerate processes, act quickly on possible changes and make periodic deliveries of work.

Initiation: In this first phase, the respective roles are identified and assigned, who will be the Scrum Master and the Stakeholders; the members of the work teams are defined according to their abilities and contributions to the project.

Planning and Estimating: In this second phase, the user stories are created, the sprint backlog will also be carried out taking into account the estimation for their correct implementation of each one of them.
Implementation: In this third phase, the respective prototypes are designed, taking into account the requirements of each of the stories raised.

Reviews and Retrospectives: In this fourth phase, the respective review of the Sprint by the team is carried out, in an activity that allows the inspection and adaptation of the product, the most important thing is the conversation by the team to understand the situation and receive feedback. In Figure 1 we can see the flow that the Scrum methodology follows.

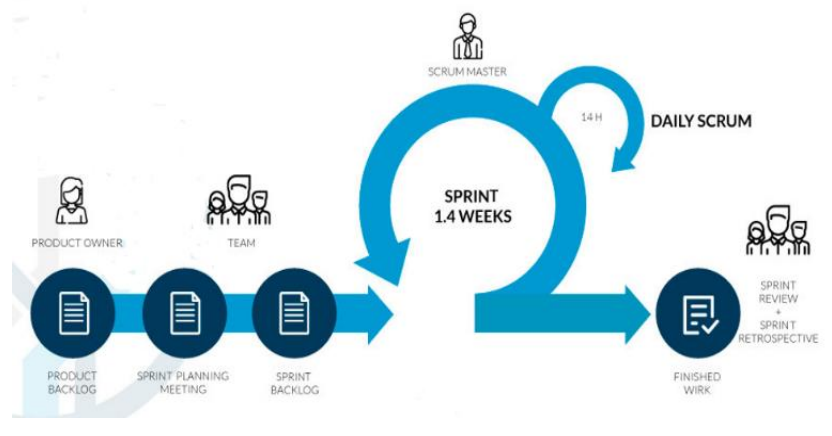

Fig.1. Scrum methodology outline.

\section{B. Technological Tools}

The technologies used for this research work guarantee an optimal development of the mobile application based on the knowledge of the members, managing to finish it according to the specifications and in the established time.

Machine Learning: This technology is a branch of Artificial Intelligence (AI) [9], that seeks to provide a software with the capacity for learning based on data and through the latter, patterns and opportunities arise through which performance tests are carried out to measure efficiency based on the percentage of errors and successes, machine learning is not Linear adapts through learning to new cases or situations, even not needing constant supervision. In Figure 2 we see how the various technologies that make up the field of artificial intelligence are divided. Figure 3 shows us in detail the steps to be taken so that the artificial intelligence software can create a learning model. 


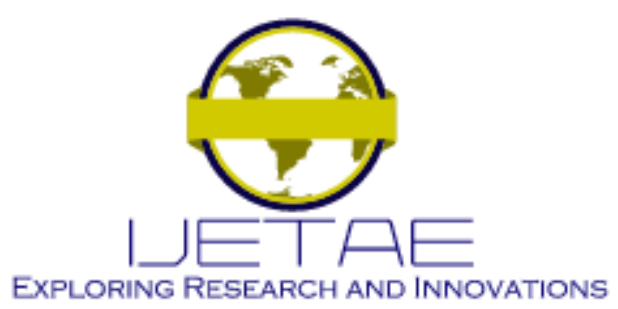

International Journal of Emerging Technology and Advanced Engineering

Website: www.ijetae.com (E-ISSN 2250-2459, Scopus Indexed, ISO 9001:2008 Certified Journal, Volume 12, Issue 02, February 2022)

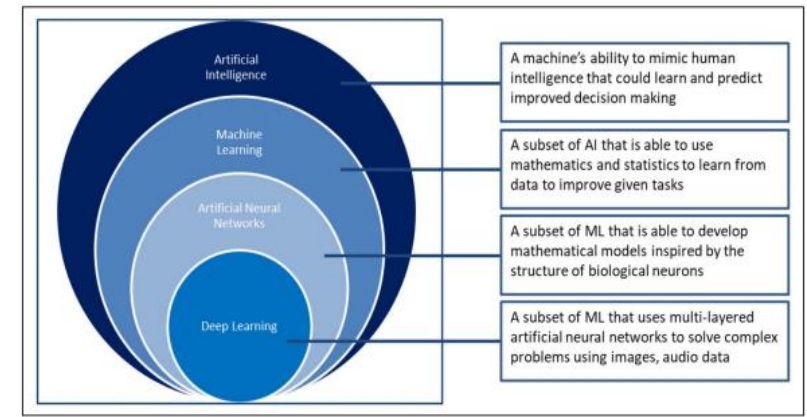

Fig.2. Graph showing how AI is classified. [10]

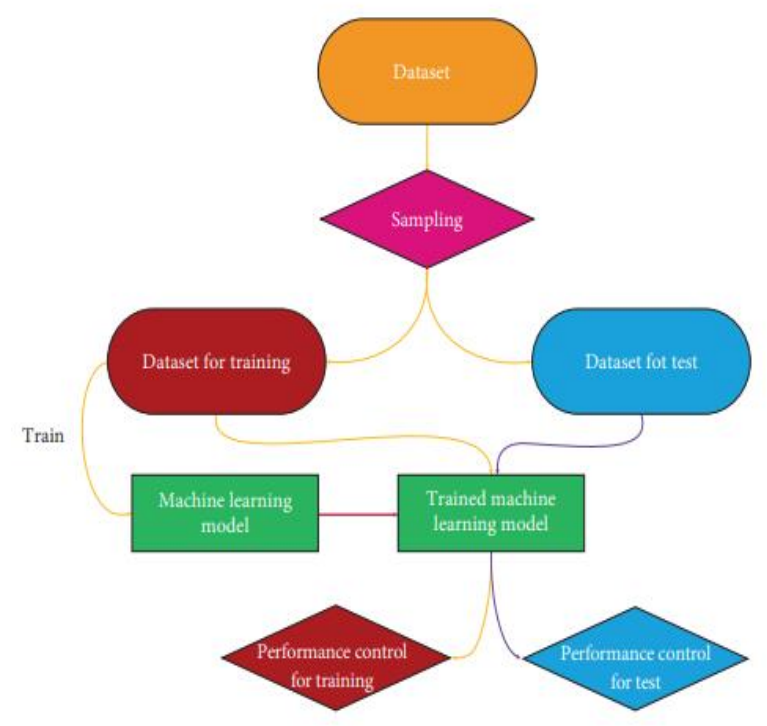

Fig.3. Machine Learning application flowchart [11].

Mobile Apps: We refer to programs designed for exclusive use on mobile devices, usually smartphones, which allows the user access to various services and functions, both professional, entertainment, educational, among others, facilitating the development of their activities. Through a survey conducted by OSIPTEL [12] The high index of mobile phone users at the national level during the last 4 years is verified.

SQL Server: It is a relational database management system (RDBMS). It supports a wide variety of transaction processing, business intelligence, and analytical applications in corporate IT environments.
Xamarin: It is a development platform that allows you to build multi-platform mobile applications. The main advantage of Xamarin is being able to develop applications that work on any type of mobile device (iOS, Android or Windows) with the same programming code, written in the $\mathrm{C}$ \# language with the .NET framework.

Python: It is a high-level programming language that manages to process all kinds of data structures, whether text or numeric. It has taken characteristics of its predecessors, it is free software, that is to say, open source and allows it to be used and distributed freely even for commercial use. It is accessible, simple and multiplatform, for this project it represents a great advantage due to its wide library, selection of frameworks and its simplicity in syntax.

\section{CASE STUdy}

\section{A. Planning}

The realization of this project includes several stages where you start by selecting the requirements and functions of the application that must be completed in a certain time. Through the user stories, the characteristics and functions of the platform are detailed based on the requested requirements.

The requirements of this project are proposed based on the dissatisfaction of citizens regarding the management of the health system in our country, in Fig. $433.4 \%$ and $43.5 \%$ of respondents consider that a service to improve is the appointment process In MINSA and ESSALUD respectively, $43 \%$ also think the main problem in health care is waiting time, although the information is from 2016, a more recent IPSOS 2021 survey reveals that the problem has not diminished since $74 \%$ of those surveyed consider that the waiting times to be attended are excessive.

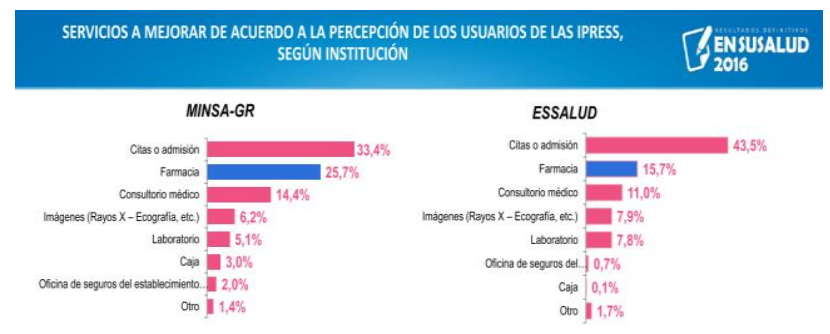

Fig. 4 Satisfaction survey of the National Health Superintendence 2016 [1] 


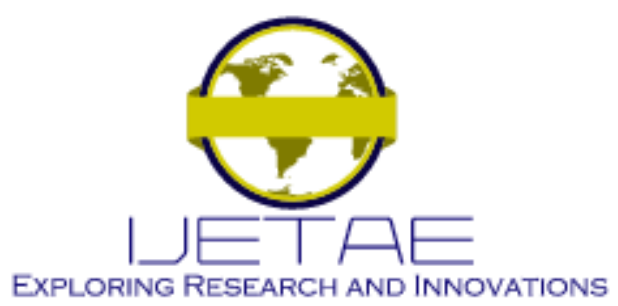

International Journal of Emerging Technology and Advanced Engineering Website: www.ijetae.com (E-ISSN 2250-2459, Scopus Indexed, ISO 9001:2008 Certified Journal, Volume 12, Issue 02, February 2022)

Once the requirements have been defined through the user stories, we proceed with the estimation and priority, which allows us to assign an order to carry out the advances which will be grouped into a total of 3 sprints placed from least to greatest difficulty. The project will have 10 user stories with an estimated time of 17 weeks for the stories to be finalized, in Table 1 we can see what each story consists of in greater detail.

TABLE 1. USER STORIES

\begin{tabular}{|c|l|}
\hline Nro & \multicolumn{1}{|c|}{ User Stories } \\
\hline U1 & $\begin{array}{l}\text { As a user, I want an interface with a friendly and easy-to-use } \\
\text { environment. }\end{array}$ \\
\hline U2 & $\begin{array}{l}\text { As a user, I want to be able to choose the specialty where I } \\
\text { will be treated. }\end{array}$ \\
\hline U3 & $\begin{array}{l}\text { As a user, I want to be treated according to the priority of } \\
\text { my case. }\end{array}$ \\
\hline U4 & $\begin{array}{l}\text { As a user, I want to be notified in case it can be attended to } \\
\text { much earlier. }\end{array}$ \\
\hline U5 & $\begin{array}{l}\text { As a user, I want to receive a notification in case my } \\
\text { appointment is canceled or rescheduled for any reason. }\end{array}$ \\
\hline U6 & $\begin{array}{l}\text { As a user, I want to review a summary of my medical } \\
\text { history. }\end{array}$ \\
\hline U7 & $\begin{array}{l}\text { As a user, I want to check the availability for medical } \\
\text { appointments according to each specialty. }\end{array}$ \\
\hline U8 & $\begin{array}{l}\text { As administrator I want the platform to detect according to a } \\
\text { medical database which patients should be treated by } \\
\text { priority. }\end{array}$ \\
\hline U9 & $\begin{array}{l}\text { As an administrator I want the platform to be able to quickly } \\
\text { organize medical appointments. }\end{array}$ \\
\hline U10 & $\begin{array}{l}\text { As an administrator I want the process of medical } \\
\text { appointments to be more efficient avoiding long waiting } \\
\text { times. }\end{array}$ \\
\hline
\end{tabular}

\section{B. Implementation and Development}

For this phase, the progress of the defined user stories is carried out and how each function is incorporated and put to the test. In Fig. 5 a graph is shown with the steps that all machine learning software follows for its training and learning process.

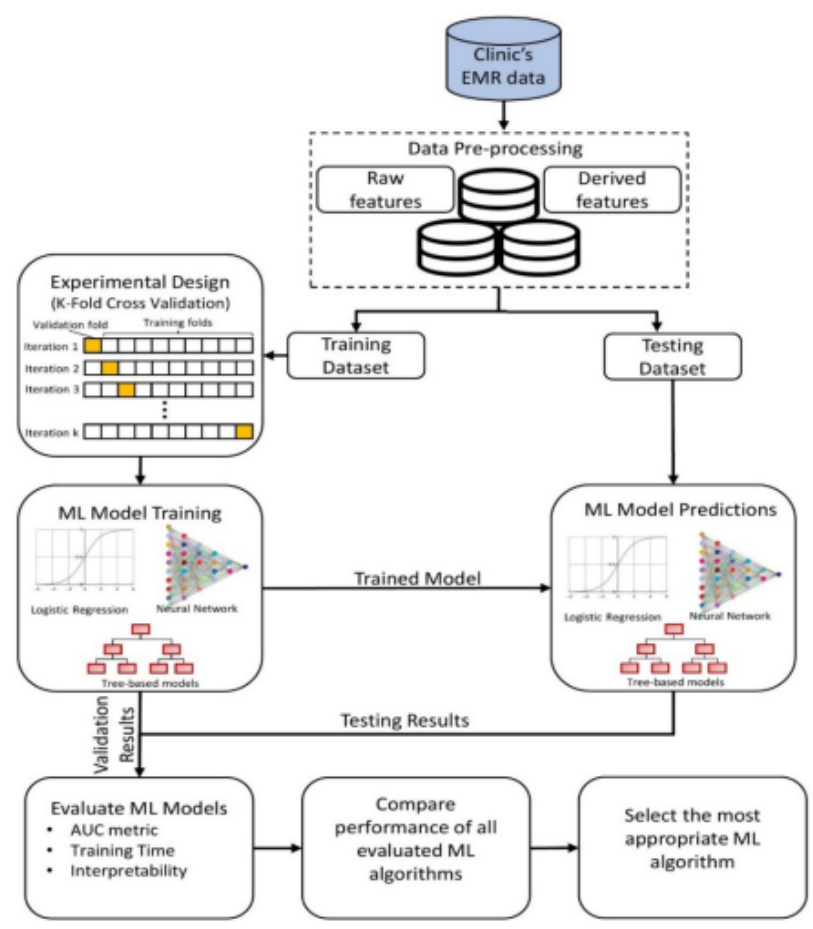

Fig. 5 Diagram of the process to choose the algorithm and subsequent Machine Learning model. [13]

Analysis and training process of the Machine Learning model: In this part of the development of the mobile application we focus on obtaining and analysing the data that we will use to prepare the machine learning modeling, it is recommended that all medical records, mainly that of medical records, be digitized, and at this stage we make the choice of the algorithms that will be used for learning artificial intelligence software.

Supervised and Unsupervised Learning: Machine learning is divided into 2 types of methods, for the application of the project both alternatives are chosen by the use of classification and regression algorithms in addition to allowing developers to better recognize the actions of artificial intelligence software and in turn have better control of the training material for the learning process. 


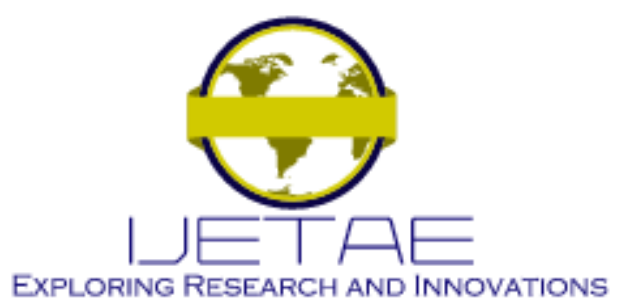

International Journal of Emerging Technology and Advanced Engineering

Website: www.ijetae.com (E-ISSN 2250-2459, Scopus Indexed, ISO 9001:2008 Certified Journal, Volume 12, Issue 02, February 2022)

Dataset: The clinical history and triage data will be divided into two parts, the first for testing and the second for training, the latter being used to achieve the most adequate possible Machine Learning modeling and with the least margin of error.

Algorithm: The algorithms that the Machine Learning software is going to use are chosen, 2 in particular are chosen because they have proven to be efficient and perform well in other similar projects:

K-Means Clustering: It is an iterative and classification algorithm; it allows solving problems without the need to label the data. Its objective is to divide a set of data into a certain amount of subgroups that are different from each other and not overlapping based on their characteristics, where each data belongs only to a single group. Fig. 6 shows a data set that is divided once the algorithm performs the grouping operation, the number of groups will depend on the number that we assign to the variable $\mathrm{k}$ in the process.
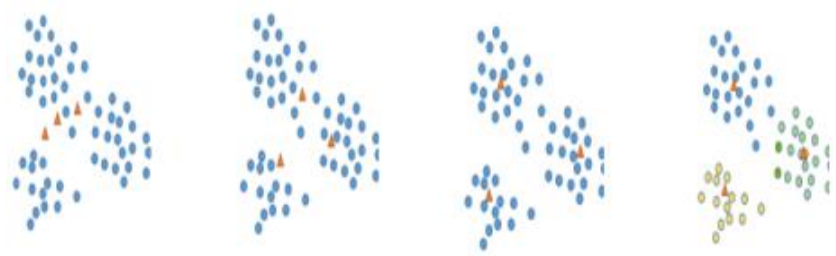

Fig.6. Algorithm K-Means

For the present project, this algorithm is chosen due to the results obtained in the research [14] where the K-Means algorithm is used to classify patients according to the triage data provided, obtaining 2 classifications, one high and the other low, as shown in Fig. 7, previously the characteristics of the symptoms must also be classified to choose the better dataset with the most important characteristics and to be able to start training the algorithm.

\begin{tabular}{|c|c|c|c|c|c|c|c|}
\hline Priority class & day 1 & day 2 & day 3 & day 4 & day 5 & day 6 & day 7 \\
\hline 1 & 15 & 12 & 9 & 6 & 3 & 0 & 0 \\
2 & 20 & 17 & 14 & 11 & 8 & 5 & 2 \\
\hline
\end{tabular}

Fig.7 Result of appointments that can be scheduled according to the data set used for the investigation [14].
XGBoost: It is a prediction algorithm that is characterized by its speed and performance when working with large datasets, fast results are achieved when training a Machine Learning model even performing parallel calculations on a single machine. Fig. 8 shows us the algorithm process that consists of a sequential assembly of decision trees in order to learn from the results of the previous trees, managing to correct errors and thus improving the algorithm with each iteration until they cannot be performed more fixes.

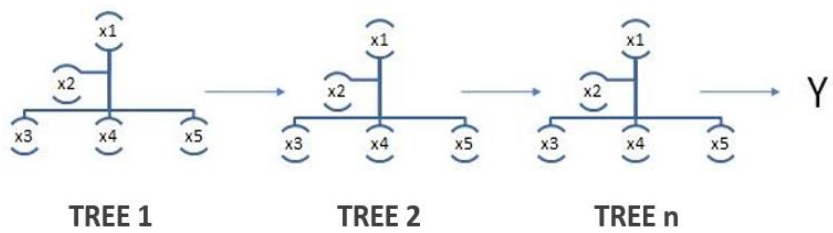

Fig.8 Algorithm Xtreme Gradient Boost

For the present project, the advantage of this algorithm is used to be able to accurately predict the number of patients who arrive for admission to obtain an appointment, in this way the available personnel can be better programmed. It is evidenced in research [15] favourable results to anticipate patient demand through the use of triage information and clinical history, achieving $0.93 \%$ efficacy in the AUC test as shown in Fig. 9

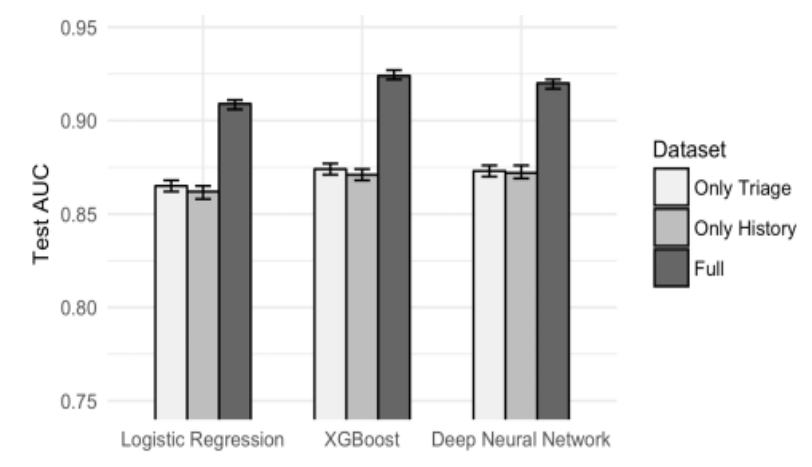

Fig.9 Comparison between algorithms confirms that XGBoost turns out to be the one with the best performance [15].

Modeling: The training of the Machine Learning model is continued until all the data has been used after that, the test data begins to be used to corroborate the efficiency and performance of the structured model. Through constant tests and evaluations, the Machine Learning model is optimal and can be implemented in the management of medical appointments. 


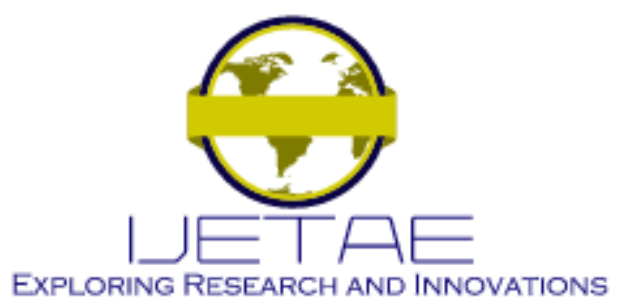

International Journal of Emerging Technology and Advanced Engineering Website: www.ijetae.com (E-ISSN 2250-2459, Scopus Indexed, ISO 9001:2008 Certified Journal, Volume 12, Issue 02, February 2022)

\section{Running the mobile application}

Figures The application is a means of communication between the server of the health institution that is in charge of storing the database that contains the information of medical records, as well as the scheduled hours and availability of the health center specialists.

The Machine Learning model through the implemented algorithms are in charge of processing the information provided by the user, determining the priority of the appointment according to the symptoms registered in the app at the same time the database is reviewed where the availability of schedules based on the urgency of the case. In Fig. 10 we see how the app communicates with the services and systems that manage medical appointments.

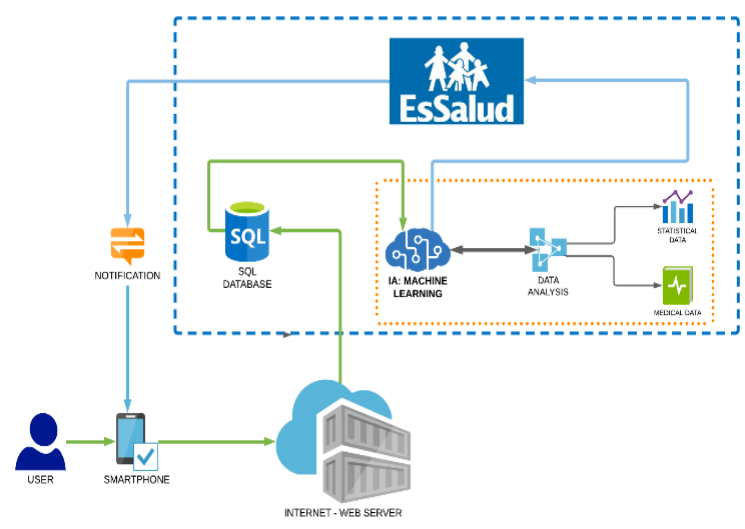

Fig.10 Mobile application software architecture diagram.

Once the information analysis has been carried out by artificial intelligence, the user is notified through the same application of the data of the entered appointment, in case any symptom or information is not in the database, it will be saved and analyzed later. this way the system continues in constant growth of data and learning for future cases.

In order for the user to be able to use the app, they must be previously registered and be insured at the ESSALUD service, which allows the application to identify their electronic medical record or, failing that, to create one for them if they are using their insurance for the first time. In Fig. 11 the process of registering medical appointments is detailed once the user has accessed the app through their Smartphone, fills out a questionnaire based on questions through the triage protocol according to their answers and the schedules are confirmed. whether or not there is availability to be attended.

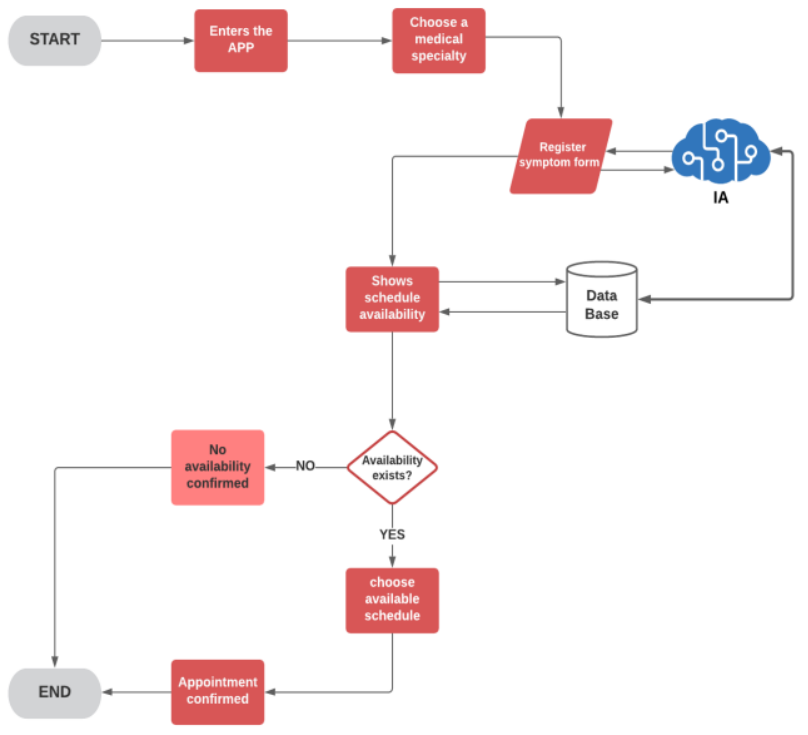

Fig. 11 How the app works through a flow chart

System Checks: In the final stage of development, tests are carried out to verify that the software is working according to the requirements set out in the initial stages, it is verified that the results are congruent to what is sought to be obtained from the application and according to the basis of data provided by the health center, the support of the medical specialists involved in the various areas is used so that they can corroborate the responses and decisionmaking of the application, in case of continuing to find errors, we proceed to continue with the improvement of the learning model used by artificial intelligence.

\section{RESUlTS AND DisCUSSIONS}

\section{A. Prototypes}

The prototypes designed based on the needs and requirements of the application are shown below.

Access to the app: The session start menu is made, a logo for the app is also designed, in Fig. 12 it is observed the possibility that the user can use social network accounts to choose a faster way to register, in Fig. 13 we see the form that must be filled out in case you do not want to use some other type of account to register. 


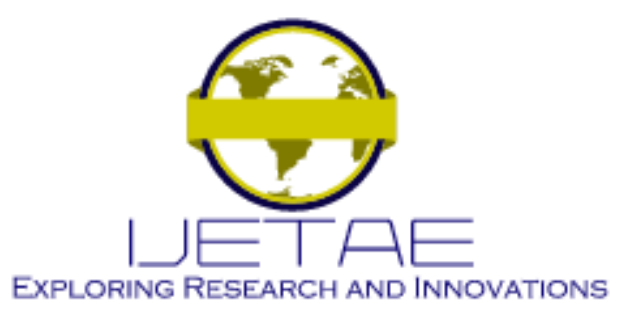

International Journal of Emerging Technology and Advanced Engineering

Website: www.ijetae.com (E-ISSN 2250-2459, Scopus Indexed, ISO 9001:2008 Certified Journal, Volume 12, Issue 02, February 2022)

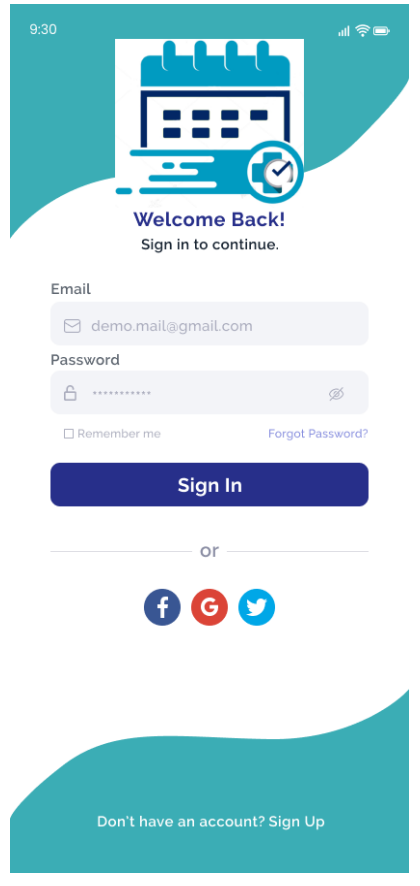

Fig.12 Login Menu

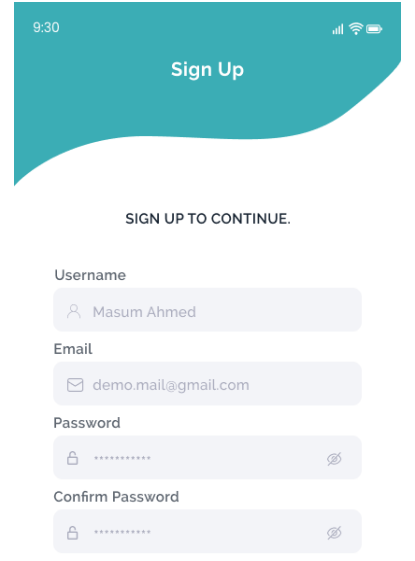

Sign Up

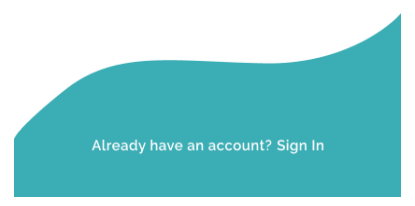

Fig.13 User register

Application interface: Once the user enters, the following interface appears as shown in Fig. 14, it is possible to observe in detail all the functions that the app has, mainly that of choosing a category to be able to register their appointment and be attended.

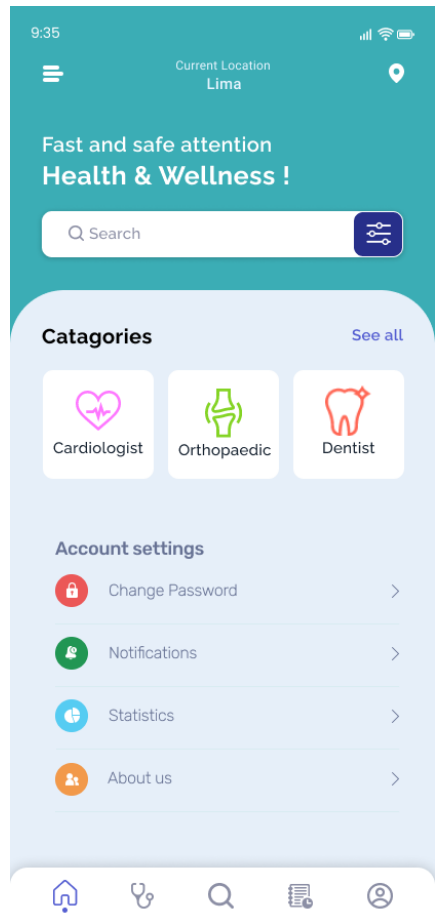

Fig.14 Main menu

Appointment record: After choosing the category where he wants to be treated, the user must register the symptoms that he is presenting in addition to placing his insured number at the ESSALUD service which allows him to be identified and to be able to correctly program the day that he will be treated, if he does not have a number of insured will not be able to continue with the process. In Fig. 15 the user chooses the date and time that can be attended according to the availability that the application shows once the entered data has been processed, in Fig. 16 the correct registration of the medical appointment is confirmed by a message. 


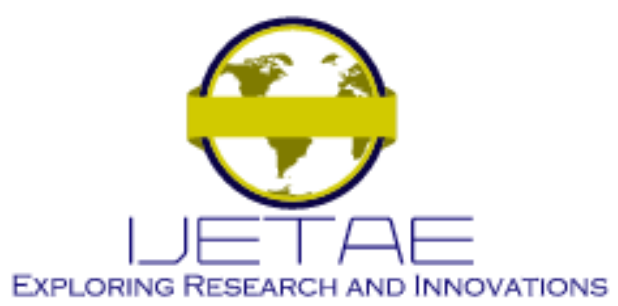

International Journal of Emerging Technology and Advanced Engineering

Website: www.ijetae.com (E-ISSN 2250-2459, Scopus Indexed, ISO 9001:2008 Certified Journal, Volume 12, Issue 02, February 2022)

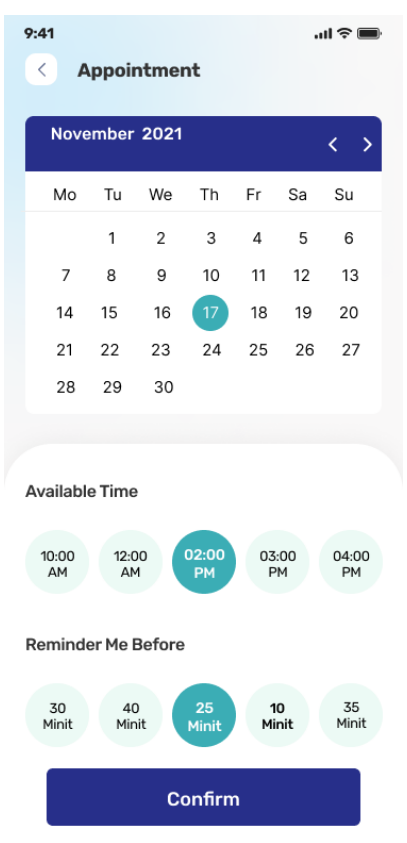

Fig.15 Hours available

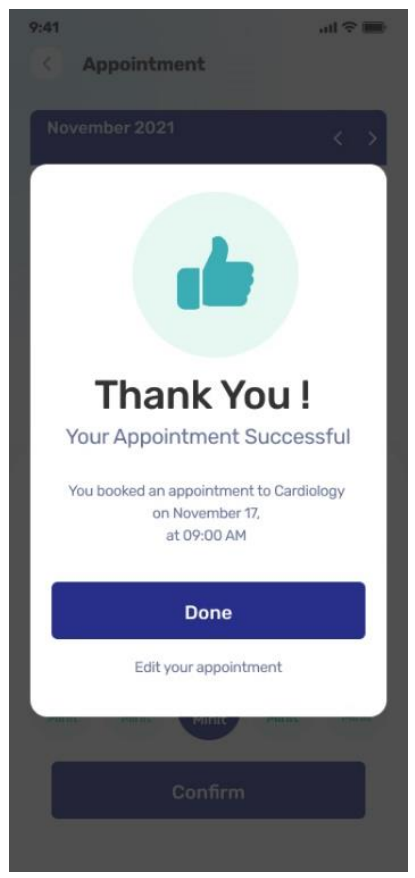

Fig.16 Confirmation message

Notifications and Reminders: The user receives a reminder of their scheduled appointment according to how they have chosen the frequency to be notified, as seen in Fig. 17 the notification can appear on the home screen of the device without the user entering the app, in Fig. 18 the user can see the history of notifications that he has received, as well as be alerted if there is availability in case another patient has canceled an appointment giving the possibility that the user can use that quota.

Scheduled Appointment Cancellation: The user has the option of canceling their appointment from the app at any time, thus giving the opportunity for their place to be occupied by another user, who will receive a notification of the availability of the shift and which must be accepted for rescheduling the appointment, the alternative of having another patient's turn will be based on the order of registration.

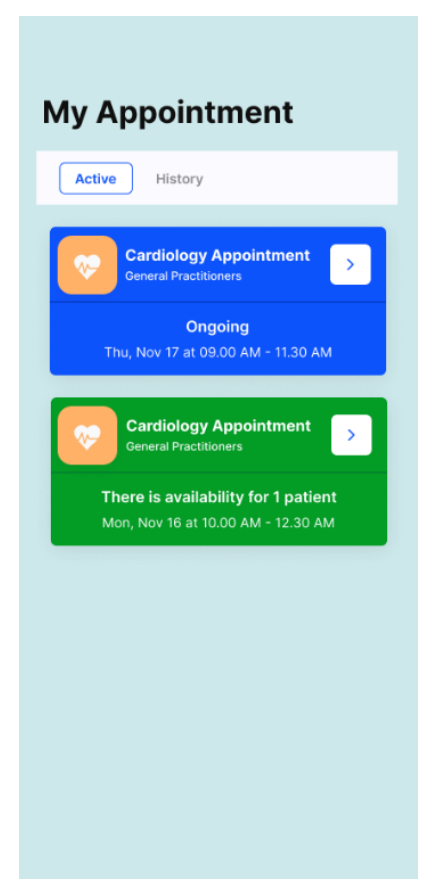

Fig.17 Reminder message

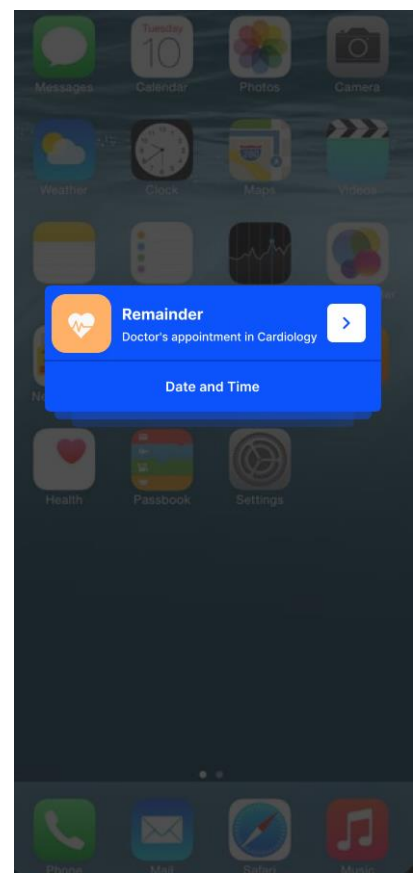

Fig.18 Reminder history

\section{B. Health management}

Approximately $85 \%$ of the health centers in Peru belong to the State, as a consequence the administration falls on its authorities, this work seeks to reduce the impact that is generated due to the deficiencies of the Peruvian health system, among its main causes are the difficulty in accessing services, the excessive waiting times to be attended and the lack of personnel, which causes great discomfort among users. In Fig. 19 a survey carried out by the Pontifical Catholic University of Peru - Institute of Public Opinion (IOP-PUCP) [16] It shows us the percentage of citizen satisfaction with respect to the care received in various health centers where ESSALUD has only $32.6 \%$ approval, well below the $59.5 \%$ obtained by a pharmacy or drugstore. 


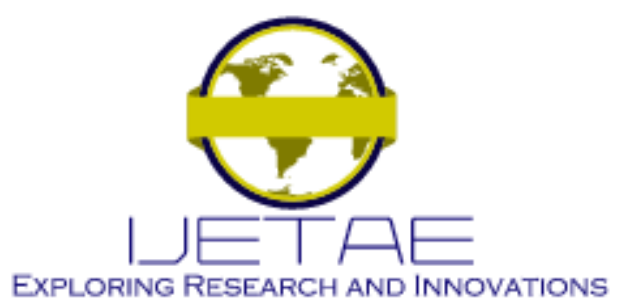

International Journal of Emerging Technology and Advanced Engineering Website: www.ijetae.com (E-ISSN 2250-2459, Scopus Indexed, ISO 9001:2008 Certified Journal, Volume 12, Issue 02, February 2022)
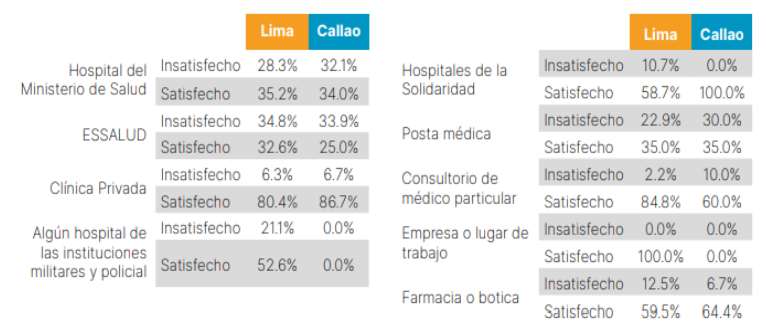

Fig.19 Satisfaction survey carried out in 2019 based on a sample of 2,320 people from Lima and Callao.

On the other hand, IPSOS in its Global Health Service Monitor 2021 survey [17] confirms that only $19 \%$ of those surveyed in Peru consider that the quality of the health system is good, therefore, through these results we can conclude that Peruvian citizens are dissatisfied as a result of poor management of the health sector in the country.

\section{Automation and access to health services}

The difficulty in accessing health services in Peru represents one of the problems that prevent rapid attention from users, in addition to the current situation worldwide, the situation worsened, making access even more difficult, IPSOS in its survey [17] highlights the opinion of users in the face of this dilemma. In Fig. 20 the interviewees are asked how much they agree with the following statement "I find it easy to get an appointment with a doctor in my area" as a result, only $27 \%$ completely agree with the statement.

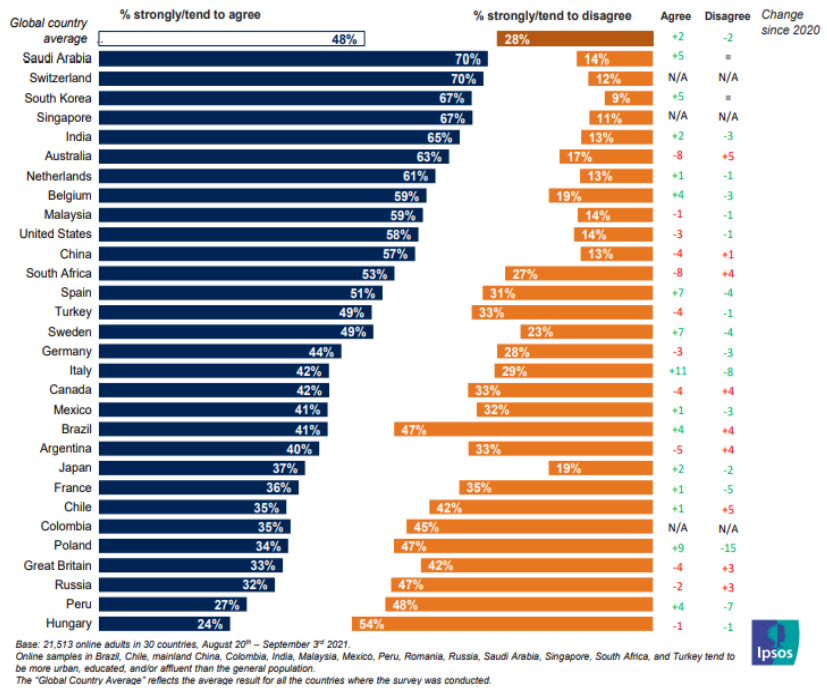

Fig.20 $48 \%$ of those surveyed consider that it is difficult to obtain a medical appointment to be seen.
The automation for the process of admission and registration of appointments generates a significant change, the present work results in a shorter, faster and safer process. In Fig. 21 we can see the difference between the available means to obtain a medical appointment in the country, while to make a request in person, up to 7 actions are carried out, doing it by mobile application only involves carrying out 3 simple steps without mentioning the time savings for the user to request an appointment from their mobile device without the need to move from one place to another and, in turn, avoiding the crowding of people in health centers, consequently it is facilitated to user access to health services by scheduling a medical appointment through their mobile device.

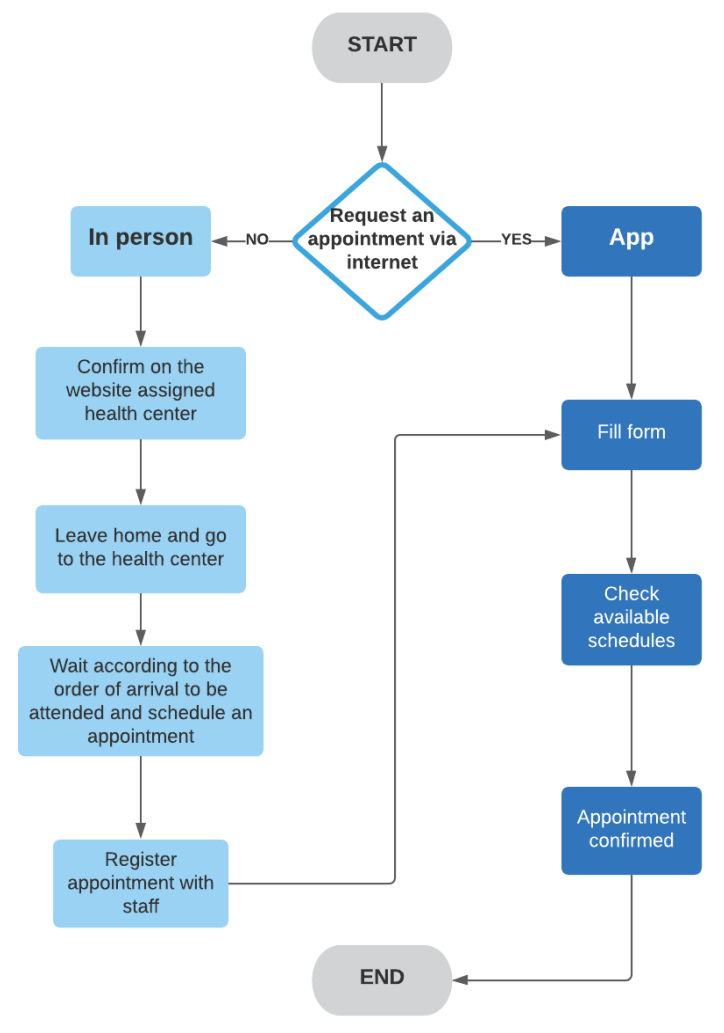

Fig.21 Steps that the user must take so that he can schedule a medical appointment in person or virtually. 


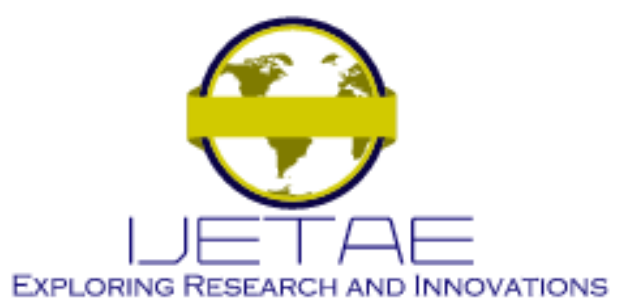

International Journal of Emerging Technology and Advanced Engineering Website: www.ijetae.com (E-ISSN 2250-2459, Scopus Indexed, ISO 9001:2008 Certified Journal, Volume 12, Issue 02, February 2022)

\section{Quality and speed of health services}

The vast majority of health centers nationwide organize their care service on a first-come, first-served basis, resulting in many patients having to wait unnecessarily to be seen. Through the IPSOS survey in Fig. 22 we observe that $51 \%$ of those surveyed consider waiting times and access to treatment as part of the main problems faced by the health system in our country. Although there are cases that merit immediate attention (emergencies), others must wait for the assigned shift, which may take between 1 to 2 weeks, causing the disease to further deteriorate the user's health and consequently complicate their future treatment.

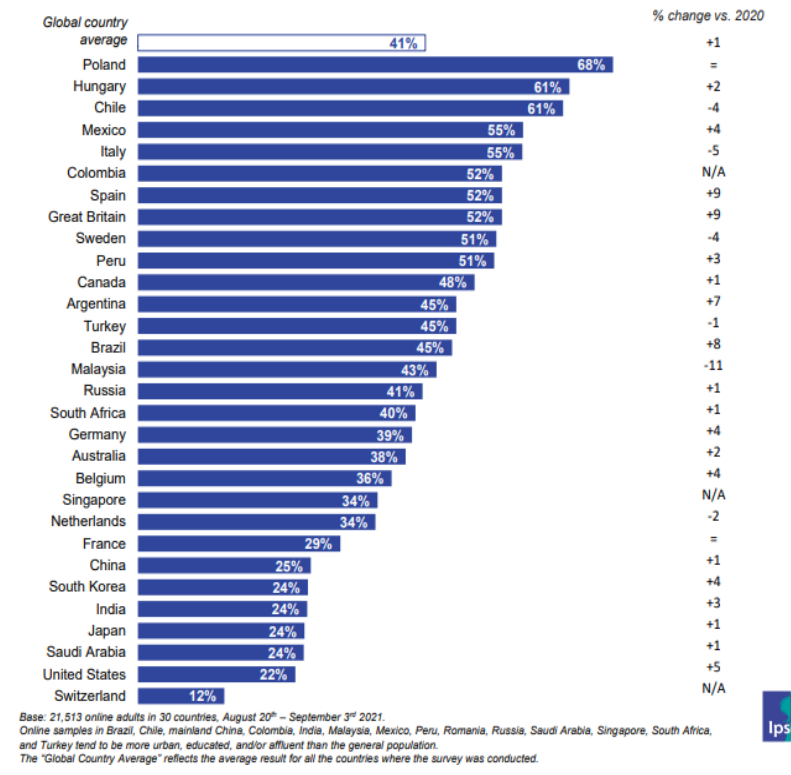

Fig. 22 IPSOS Global Health Service Monitor 2020 survey conducted during the Covid-19 pandemic

This project allows prioritizing the cases of those patients who are not considered emergency but require prompt attention based on the symptoms they manifest, through the proposed Machine Learning model and using the K-Means algorithm in the mobile app program The appointment according to a priority level and the schedule of doctors by specialty available, which translates into a reduction of the impact of the disease on the patient and therefore achieve the most timely and effective treatment for their recovery.
In this way, it is possible to provide a quality service and an improvement when assigning a medical appointment in the shortest possible time and that implies less risk and greater benefit for the user or the population.

\section{E. Supply and distribution of health personal}

According to the latest figures provided by the Ministry of Health in 2020, in Peru there are approximately 14 doctors for every 10,000 inhabitants [18] As can be seen in Fig. 23, a number below that recommended by the World Health Organization (WHO) and the Organization for Economic Cooperation and Development (OECD) [19] which indicate that there must be at least between 23 and 35 doctors for every 10,000 inhabitants respectively to guarantee adequate coverage, care and quality of service. In addition to this problem, there is an inadequate distribution of medical personnel in the country, confirming much lower figures in disadvantaged regions in terms of the number of doctors, which makes a prompt intervention and response even more difficult in the face of the current pandemic as well as the other demands of Health. Although the incorporation, training and equitable distribution of medical personnel is a way out of this problem, it is up to the competent authorities to guarantee adequate management to improve the strategies and policies of the current health system model in the country.

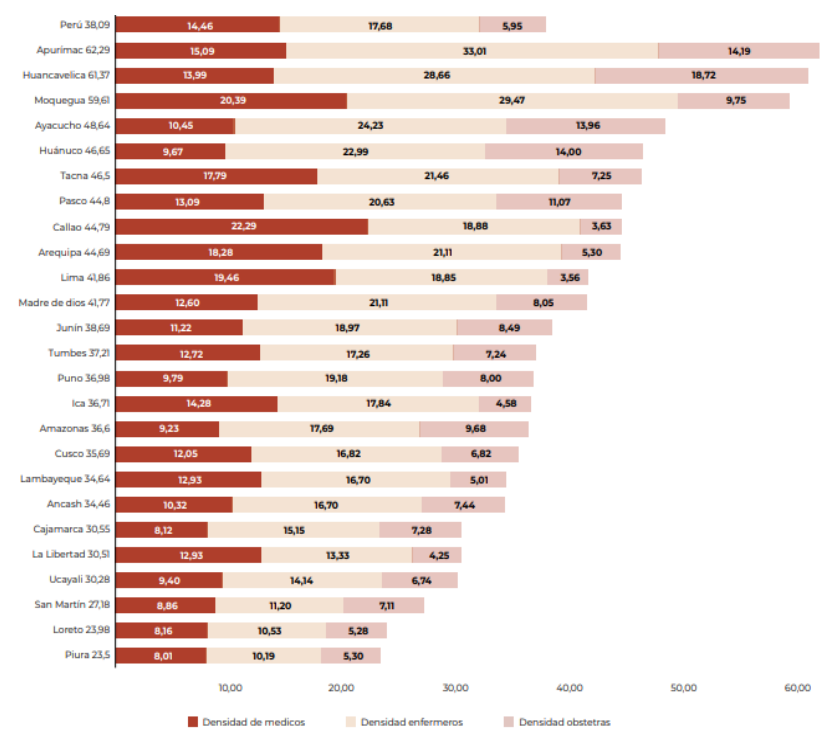

Fig.23 Information on Human Resources in the Health Sector in the Framework of the COVID -2019 Peru Pandemic: 2020. 


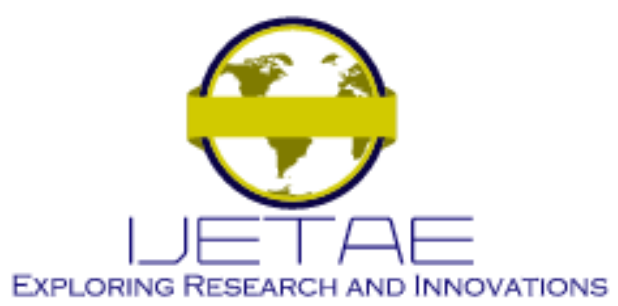

International Journal of Emerging Technology and Advanced Engineering Website: www.ijetae.com (E-ISSN 2250-2459, Scopus Indexed, ISO 9001:2008 Certified Journal, Volume 12, Issue 02, February 2022)

In this regard, the present work proposes with the use of the mobile app not only to automate the appointment process and prioritize the consultations but also to be able to predict the demand for admission and attention through the proposed Machine Learning model which, applying the XG- algorithm, Boost uses the information provided by both the application and the data obtained after consultations and patient care, the results are used by the health center to improve availability and compensate to a certain extent the deficit of the personnel in charge of this In this way, more precise planning of the health personnel's schedules is achieved, saving administrative costs and optimizing human resources, which, as we can see, are below what is recommended.

\section{CONCLUTIONS}

Finally, the present research work manages to design a mobile app that, through the application of artificial intelligence, facilitates the process of scheduling medical appointments in the public health sector in addition to offering various functionalities such as canceling an appointment, reminders through notifications, reviewing the patient's medical history. patient and confirm the corresponding health center.

The pandemic that began in 2020 exposed the deficiencies of our health system, one of the main problems being the response time to receive medical attention. The results of this project showed that the modernization of the health service has a positive impact on health management, allowing speeding up the procedures to book an appointment and be attended in the shortest possible time, facilitating the population's access to health services and granting quality care also supporting health specialists in decision-making in relation to more efficient management for the health facility, in addition to reducing the administrative work of the staff so that they can occupy most of their time in care of patients.

As a recommendation for the project, it is considered to deepen the techniques or methods that allow the digitization of physical documents used in health centers such as medical records that contain information of great importance and that provide the necessary data for the modeling process of the artificial intelligence used in the app, in addition to being able to have a system for the payment service for appointments of users who are not insured, guaranteeing that citizens can be treated equally in any public health establishment.

\section{REFERENCES}

[1] S. N. de S. (SUSALUD), "Encuesta Nacional de Satisfacción en Salud 2016: Resultados definitivos," Minsa, p. 63, 2016, [Online]. Available: http://portal.susalud.gob.pe/wpcontent/uploads/archivo/encuesta-sat-nac/2016/PRESENTACIONSUSALUD-2016.pdf.

[2] C. Maguiña Vargas, "Pandemia de la COVID-19 y su impacto en el sistema de salud peruano," Rev. Peru. Med. Integr., vol. 5, no. 3, pp. 93-94, 2020, [Online]. Available: http://dx.doi.org/10.26722/rpmi.2020.53.180.

[3] H. Villa, "La pandemia de la COVID-19 y la lucha por un sistema único de salud, universal e igualitario," Nueva Hegemonía, vol. 1, pp. 2020, [Online]. 54 Available: https://nuevahegemonia.centropatria.pe/public/uploads/articulos/202 0-09-27-09-28-46_Villa.pdf.

[4] N. Inv, "Autora: Lilia Jannet Saldarriaga Sandoval Categoría profesional y lugar de trabajo: Doctora en Enfermería, Docente de la Universidad Nacional de Tumbes-Perú," vol. 17, no. 108, pp. 1-2, 2020.

[5] J. A. Gutiérrez Martínez and A. Febles Estrada, "Hacia la medicina del 2030," UCE Ciencia. Rev. postgrado, vol. 7, no. 1, p. 2019, 2018.

[6] A. A. Rodriguez Lozano, "Analítica de datos para la optimización del agendamiento de citas médicas," instname:Universidad de Bogotá Jorge Tadeo Lozano, 2020, [Online]. Available: https://expeditiorepositorio.utadeo.edu.co/handle/20.500.12010/1048 6.

[7] G. Sobre et al., "Sistema de recomendaciones de especialidades médicas y reservas de citas para mejorar el servicio de atención al paciente en el CMU-UNSM-T," p. 112, 2020, [Online]. Available: http://repositorio.unsm.edu.pe/bitstream/handle/11458/3888/FIAI Larry Amasifuen Pinchi.pdf?sequence=1\&isAllowed=y.

[8] A. T. Porras, "Contact Center cognitivo para asignación de citas médicas y autorización de exámenes,” Pap. Knowl. . Towar. a Media Hist. Doc., 2019.

[9] S. V. Ulyanov, "Advances in Intelligent Systems and Computing," in Advances in Intelligent Systems and Computing, vol. 1095 AISC, 2020, p. 997.

[10] G. Delanerolle et al., "Artificial intelligence: A rapid case for advancement in the personalization of Gynaecology/Obstetric and Mental Health care," Women's Heal., vol. 17, 2021, doi: $10.1177 / 17455065211018111$.

[11] S. Studer et al., "Towards CRISP-ML(Q): A Machine Learning Process Model with Quality Assurance Methodology," Mach. Learn. Knowl. Extr., vol. 3, no. 2, pp. 392-413, 2021, doi: 10.3390/make3020020.

[12] Organismo Supervisor de Inversión Privada en Telecomunicaciones (OSIPTEL), "Encuesta Residencial de Servicios de Telecomunicaciones - ERESTEL 2018,” p. 16, 2019, [Online]. Available: http://www.osiptel.gob.pe.

[13] S. Srinivas, "A machine learning-based approach for predicting patient punctuality in ambulatory care centers,” Int. J. Environ. Res. Public Health, vol. 17, no. 10, 2020, doi: 10.3390/ijerph17103703.

[14] N. Yousefi, F. Hasankhani, and M. Kiani, "Appointment scheduling model in healthcare using clustering algorithms," pp. 1-24, 2019, [Online]. Available: http://arxiv.org/abs/1905.03083. 


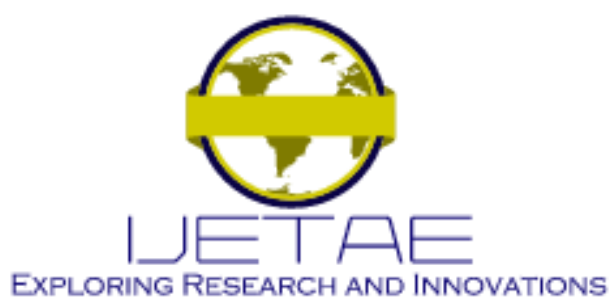

International Journal of Emerging Technology and Advanced Engineering

Website: www.ijetae.com (E-ISSN 2250-2459, Scopus Indexed, ISO 9001:2008 Certified Journal, Volume 12, Issue 02, February 2022)

[15] W. S. Hong, A. D. Haimovich, and R. A. Taylor, "Predicting hospital admission at emergency department triage using machine learning," PLoS One, vol. 13, no. 7, pp. 1-13, 2018, doi: 10.1371/journal.pone.0201016.

[16] Pontifcia Universidad Católica del Perú - Instituto de Opinión Pública (IOP-PUCP), "Lima y Callao según sus ciudadanos Décimo Informe Urbano de Percepción sobre Calidad de Vida en la Ciudad," p. 61, 2019, [Online]. Available: http://www.limacomovamos.org/wpcontent/uploads/2019/11/Encuesta-2019_web.pdf.
[17] IPSOS, “GLOBAL HEALTH MONITOR 2021," no. October, p. 34, 2021, [Online]. Available: www.ipsos.com.

[18] W. Pérez, J. Moreno, and J. Loayza, "Información de Recursos Humanos en el Sector Salud en el Marco de la Pandemia COVID 19," Minsa, 2020.

[19] T. O. for E. C. and D. (OECD), Health at a Glance: Latin America and the Caribbean 2020. 2020. 